\title{
Students Facing Examples: Making the Unseen Visible Learning in an Example-Rich Environment (ERE) - An Emotional Perspective
}

\author{
By Hava Greensfeld ${ }^{*}$ \\ Efrat Nevo
}

The purpose of our qualitative study was to explore the emotional aspects that accompany learning in an Example-Rich Environment, ERE, through the use of examples created by students in previous years. The study was conducted within the framework of the "Learning Processes" academic course at a teacher-education college, from 2010 to 2013 (N=70). The research tools were four questionnaires, a designated ERE, and observations. We adopted a unique pedagogical strategy. We determined in advance when the students could study the ERE. The students began each task by constructing an initial version; they were then asked to improve it through the study of the ERE. Content analysis revealed two main approaches: the "objecting" approach and the "agreeing" approach; these led to identification of six academic emotional types of users of the ERE. The extent to which examples were actually used or not used was examined via the dimension of each type's achievement goals. Our research highlighted the central importance of the motivational component in all that concerns academic emotions. The findings may aid in characterizing variation among learners in online environments and to explain their level of willingness to use ERE.

Keywords: academic emotions, achievement goals, learning through example

\section{Introduction}

Understanding learning processes in an example-based environment is of interest to scholars from various disciplines. This qualitative study presents the missing perspective: the emotional aspects that accompany learning in an example-based environment. Students in the school environment experience a myriad of emotions on a daily basis (Hargreaves, 2000; Pekrun, Goetz, Titz \& Perry, 2002; Zeidner, 2007). These include enjoyment, pride, curiosity, interest, anxiety, anger, envy, frustration, and boredom. Less attention has been given to other emotions (besides anxiety), which are manifested during learning experiences, and researchers have attached only minimal importance to other emotional processes and their implications (Pekrun \& Frese, 1992; Pekrun, Goetz, Titz \& Perry, 2002).

\footnotetext{
${ }^{*}$ Head of Research Unit, Michlala, Jerusalem College, Israel.

${ }^{\dagger}$ Teacher Educator, Michlala, Jerusalem College, Israel.
} 


\section{Academic Emotions}

As research into emotions in an educational context has expanded, Pekrun et al. (2002) used the concept of academic emotions to define emotions directly related to students' processes of studying, classroom instruction, and scholastic achievement. Accordingly, academic emotions will include a diversity of emotions experienced at school or university in the context of academic achievement, beyond the sense of failure or success. Pekrun et al. (2002) found that academic emotions were significantly and directly linked to five factors: the student's motivation, learning strategy, cognitive resources, self-regulation, and academic achievement; these factors were found to be related to the student's personality and previous learning experiences. They found that students in academic systems experience a rich diversity of emotions. Anxiety was frequently reported, but positive emotions were described no less frequently than negative emotions.

Over the years, several theories have been proposed (Meyer \& Turner, 2006) to explain the link between emotions and complex learning situations: a. the academic risk theory, which refers to students who are willing to take on challenging learning experiences that demand readiness to risk failure, and require the ability to control negative emotions. These are contrasted with cautious students, who choose easy tasks (Zocco, 2009); b. goal theory, which emphasizes the role of achievement: goals will evoke either positive emotions, when the student will cope successfully with the challenge, or negative emotions, which will impair the student's ability to cope with the challenge (McGregor \& Elliot, 2002); c. the control-value theory, which was developed as a framework for defining academic emotions and for constructing instruments to measure emotions in an academic context (Pekrun, Elliot, \& Maier, 2009; Pekrun \& Perry, 2014). This theory was based on previous models which viewed emotion construction as circular, moving around two bipolar dimensions (e.g., Barrett \& Russell, 1998). The two important dimensions are valence (positive versus negative) and activation (activating versus deactivating). These two dimensions were used to define academic emotions.

The proliferation of studies on academic emotions in the last decade has led to the definition of academic emotions as a multifaceted phenomenon, which involves a diversity of parallel psychological processes. These include affective, cognitive, psychological, motivational, and expressive components (Pekrun \& Linnenbrink-Garcia, 2012).

In this paper, we will use the broad definition of academic emotions coined by Pekrun et al. (2002), and hence will refer to all the emotions that were aroused in the students in the context of a given academic task as academic emotions.

The present study comes under the category of research focusing on the role of academic emotions in learning processes. This notwithstanding, it should make a contribution also in the area of identifying emotions in an academic context. Its uniqueness lies in the study of academic emotions that 
were expressed by students during an academic course set in a learning environment with which examples were integrated.

\section{Example-Based Learning}

Learning in an example-based environment is common in an educational context, whether by teachers, who bring examples to illustrate their words, or by students, who wish to see examples of a given task. In the current information era searching the Internet, including searching for examples, is common. Studies that dealt with example-based learning (Sung \& Poggio, 1998) examined three main areas: 1 . The use of examples as a conceptteaching strategy, which explored how example-based teaching (deductive/inductive) assists students in integrating new knowledge with prior knowledge (e.g., Vinner, 1983; 2011); 2. The use of worked examples as a strategy for teaching mathematical problem-solving, which offers examples concept as a stage-by-stage demonstration for solving a specific type of problem (Atkinson \& Renkl, 2007; Kalyuga \& Sweller, 2004; van Gog \& Rummel, 2010); 3. Learning from observing the demonstration by an expert, which follows an observational learning process via a demonstrated model (Bandura, 1971). Example-based learning in each of the aforementioned areas is perceived as a means to advance learning processes.

This study presents a new angle. As opposed to studies of example-based learning that focused mainly on its cognitive contribution (Atkinson \& Renkel, 2007), or on the inductive/deductive mental process, the present study addresses specifically the student's emotional process during example-based learning. The participating students were invited to construct knowledge and refine the initial version of each of the academic course tasks following an encounter with a designated pool of examples, which we named an "ExampleRich Environment" or ERE. The ERE represented a variety of possibilities for organizing the information. In this age of accessible information, understanding academic emotions that accompany learning in an ERE is highly important.

\section{The Context}

The data for this qualitative study were gathered during a one-semester Learning Processes course at a college of education in Jerusalem, part of a cluster of courses for fostering thinking at the Center for the Development of Thinking and Learning. Two facilitators, the authors of this paper, were the course instructors. The course website contained the course tasks, instructions for the learning process, texts that describe learning theories, as well as a designated ERE relevant to the various course tasks. The designated ERE was used under our direction in accordance with calculated timing. This created optimal conditions for innovative research on learning through examples, as we will describe below.

The following considerations guided us in shaping the ERE: 
1. Learning that was based on constructivist principles. The aim of the course was to expose the students to theoretical and practical aspects of learning theories, while being engaged in learning processes. During the course the students were asked to read academic texts that describe certain learning theories. They then had to write a summary and recommendations for educational implementations that reflected the organization of the information and the meaning that each student attributed to the knowledge that she gained. We allowed the students to present their tasks both textually and visually, such as through tables and figures.

2. Iterative refinement. The students were instructed to perform the course tasks in two stages: i. to create an initial version of the task without using the ERE; ii. to refine and redesign the initial version.

3. Learning through the ERE. The students were asked to refine the initial version by perusing the examples that had been created by students in previous years and to fine-tune their final version.

4. The timing of accessing the library of examples. As opposed to example based-learning, which offers students the option of using the examples as resources throughout the learning process, we (the course facilitators) adopted a different pedagogical strategy. We determined in advance when the students could study the ERE. It was made available for use only after the students had created an initial version of each task. Later, they were asked (as part of the task components) to study the examples and then to fine-tune their initial version. According to Ausubel (1968), the initial version would reflect the students' information processing, enable building new schemes in the dipper stage of learning, and engender meaningful learning.

5. Evaluating processes while using the examples. The students had to reflect on and evaluate their initial version of the task and compare it to the knowledge presented in the examples that were created by previous learners. The ERE served as a resource for self-learning.

6. Autonomy. Students' ability to choose during a learning process is perceived as motivation-enhancing (Linnenbrink \& Pintrich, 2003; Pugh \& Bergin, 2006). Thus, after the student had built an initial version, we enabled them free usage as each student chose.

The academic demand to study other students' examples exposed academic emotions in the learning process, which are the focus of the present study.

\section{The Research Question}

Which academic emotions are manifested in the learning process among students studying in an ERE (example-rich environment)? 


\section{Method}

\section{Participants}

The participants were 70 women on sabbatical or in educational in-service training, who took the one-semester course between 2010 and 2013. The course students were teachers who filled a variety of roles in the education system: elementary and high school homeroom teachers, math and science teachers, special education teachers, music and drama therapists, occupational therapists, and speech therapists. Their ages ranged from 22 to 55 .

The participants were informed about the purpose of the research and gave their written agreement to participant in it.

\section{Research Tools}

1. Four open questionnaires which were distributed at various stages of the course: At the beginning (Questionnaire 1) the student were asked general questions about using examples, such as: Would you like to use examples while working on your course-tasks? Two intermediate questionnaires (Questionnaires 2 and 3 below): On completion of each task, the participants were asked to fill in a questionnaire about their process thus far, such as "Describe the process you underwent and how you felt while using the ERE". In addition they were asked to evaluate their actual degree of usage of the ERE on a scale from 0 to 3 ( $3=$ maximum use). On completing the learning process of the course, the students were asked to answer a summative questionnaire, related to the entire learning process in an ERE.

2. A designated ERE, prepared by students from previous years (169 files). The ERE served as the experimental learning environment. It was made available for use only after the students had created an initial version of the task.

3. Participatory observations by the two researchers, who were also the course facilitators. In each meeting of the course one of us served as the facilitator, and one of us was the observer. Both of us wrote field notes which included the narrative of classroom events, conversations in the classroom, quotations of particular students, and descriptions of behaviors related to the library of examples. The classroom observations were then compared for triangulation across researchers (Patton, 2002).

\section{Data Analysis}

We performed a content analysis of the data using the grounded theory approach (Charmaz, 2006; Corbin \& Strauss, 1998). The coding categories were derived partly by a process of inductive analysis (Corbin \& Strauss, 1998; Patton, 2002) and partly by research on emotions in general (e.g., Linnenbrink, 2006), and on academic emotions specifically (e.g., Pekrun, Goetz, Titz \& 
Perry, 2002). The sum total of all the participants' questionnaires was 273 questionnaires. Analysis of these questionnaires was done by the two facilitators of the course in four stages. During the first stage, a set of four questionnaires of seven students (28 in all) were selected at random. Each coder was required to analyze the questionnaires independently and devise a set of categories that could account for the learning processes demonstrated in the questionnaires.

After completing the initial open coding, the categories were compared and a coding scheme was established, on which $95 \%$ of the agreement was reached. Each researcher then employed this new coding scheme to code independently a new set of 28 randomly selected questionnaires. The results were compared again, and the coding scheme was further refined. In this stage (see Table 1) a total of three main categories were generated: Actual usage of the ERE (used or not used), academic emotions, and the valence of the emotions toward the ERE. Analysis of the open questions revealed many expressions linked to the academic emotions that accompanied the learning process. These included affective aspects such as happiness, enjoyment, tranquility, sense of threat and self-blame; cognitive aspects such as curiosity, interest, mental block; physiological aspects such as a light in the eyes; and motivational aspects such as lethargy, lack of motivation, and willingness to make an effort. While sorting the academic emotions we found positive emotions such as happiness, enjoyment and curiosity, versus negative emotions such as sense of threat, fear and confusion. These two aspects have been defined in the literature as positive valence and negative valence (e.g., Barrett \& Russell, 1998).

In the second stage the three main categories were tested by the two coders while analyzing all 273 questionnaires. This third iteration with all of the questionnaires revealed a core category: The preferred approach toward the ERE: the agreeing approach and the objecting approach. This category included three sub-categories: i. Using or not using the examples, ii. which emotions were involved, and iii. their valence (positive or negative). In this paper, we will not examine the preference of one approach over the other for advancing the learning process in an ERE.

In the third stage we coded each set of four questionnaires from each student in axial coding. In total we analyzed 252 questionnaires (four questionnaires * 63 students from whom we had full sets of questionnaires.). In this stage, two main categories were defined: The degree of usage of the ERE refers to the degree to which each student actually used the ERE, on a scale from 0 to 3 ( 3 = maximal usage). The second main category was the participants' type of emotional process experienced while learning in an ERE. We identified three types of academic emotional processes: a. A learning process in which unpleasant academic emotions were aroused in relation to learning in an ERE. These emotions were expressed immediately after the students received the first course task, even before they had opened the ERE, and the same emotions continued throughout the entire learning process. Statements such as "I didn't like the idea of using examples from the 
beginning" were common; b. A learning process in which pleasant academic emotions were aroused toward learning in an ERE; c. A learning process that was characterized by changes in the emotional valence with which the students entered the ERE. Three sub-categories of changes in the emotional valence were identified throughout the learning process in an ERE, for example: "In the beginning I felt frustration and confusion, and then [after using the ERE] I felt satisfaction that I had understood and performed the tasks successfully" (a change from negative to positive valence).

Table 1 presents the process in which the categories took form over 3 (of the 4) stages of the data analysis.

In the $4^{\text {th }}$ stage of the coding process we looked for explanations of the various academic emotions that were expressed, their valence, the kind of the approach toward using the ERE, the degree of actual usage and the type of emotional processes while learning in an ERE. While contemplating these explanations we realized that the category of approach toward an ERE (agreeing/objecting) is a meta-category that explains the overall academic emotions of learners in such an environment. This category reflects the learner's consistent internal attitude toward using examples created by others. That attitude draws on a new core category that was discovered during the data analysis: the type of achievement goals.

The importance of students' achievements in an academic context is wellknown. Examining the data via the achievement-goal-focused theory added further depth to understanding the academic emotions of the participants in the ERE. This theory emphasizes the role of the goals in predicting academic emotions that will be aroused with exposure to certain goals (Dweck, 1999; Meyer \& Turner, 2006). Two types of goals - mastery goals and performance goals - appear to motivate students to work on an academic task (Pekrun et al., 2009). Students focused on mastery goals aspire to develop new skills, to understand their current task, to improve on their present achievements, and to master the field of study. Analyzing the data revealed statements that reflected the mastery-goals of students learning in the ERE as illustrated by Carol's words (all the real names have been changed): "Using the ERE enabled me to develop a range of ideas, styles and formulations and then to choose the ones that would work best for me in enhancing my learning".

Focusing on mastery goals maintains a high academic self-concept, and might also prevent negative academic emotions such as anxiety while coping with challenges or failure. In contrast, students who focus on performance goals aspire to be the best and to obtain higher grades than others, and thus are preoccupied with evaluating their ability in comparison to their peers. This approach might cause them to have negative feelings and to worry about other people's achievements instead of focusing on the task at hand. We found statements such as: "While comparing my assignment to those represented in the examples, I felt stupid and frustrated. They did a much better job than me, even though I'm working so hard to get a high mark in this course" (Shirley). Studies have shown that more mastery-focused learning has an impact on learning quality. It is noteworthy however, that performance-focused learning does not necessarily 
contradict mastery-focused learning (Senko, Hulleman, \& Harackiewicz, 2011).

In the discussion section we will consider how the two core categories (approach toward the ERE and learner's type of achievement goal) construct the academic emotional types of users of ERE.

Table 1. The Coding Process

\begin{tabular}{|c|c|c|c|c|}
\hline Stages & $\mathbf{N}$ & \multicolumn{3}{|c|}{ Categories } \\
\hline $\begin{array}{l}\text { 1a. open } \\
\text { coding }\end{array}$ & $28^{\mathrm{a}}$ & & & \\
\hline $\begin{array}{l}\text { 1b. open } \\
\text { coding }\end{array}$ & $28^{b}$ & \multicolumn{3}{|c|}{ 1. Actual usage of the ERE } \\
\hline & & \multicolumn{3}{|c|}{$\begin{array}{l}\text { a. used } \\
\text { b. not used }\end{array}$} \\
\hline & & \multicolumn{3}{|c|}{ 2. Academic emotions } \\
\hline & & \multicolumn{2}{|c|}{ a. Aspects } & Expressions \\
\hline & & \multicolumn{2}{|c|}{ i. affective aspects } & $\begin{array}{l}\text { happiness, tranquility, sense of } \\
\text { threat, self-blame, enjoyment }\end{array}$ \\
\hline & & \multicolumn{2}{|c|}{ ii. cognitive aspects } & curiosity, interest, mental block \\
\hline & & \multicolumn{2}{|c|}{ iii. physiological aspects } & light in the eyes \\
\hline & & \multicolumn{2}{|c|}{ iv. motivational aspects } & $\begin{array}{l}\text { lethargy, lack of motivation, } \\
\text { willingness to make an effort }\end{array}$ \\
\hline & & \multicolumn{2}{|c|}{ 3. Emotional valence } & \\
\hline & & $\begin{array}{l}\text { a. positive } \\
\text { b. negative }\end{array}$ & & \\
\hline \multirow{3}{*}{$\begin{array}{l}\text { 2. open } \\
\text { coding }\end{array}$} & 273 & \multicolumn{2}{|c|}{ 1. Approach toward ERE } & \\
\hline & & \multicolumn{2}{|c|}{ a. Agreeing } & b. Objecting \\
\hline & & \multicolumn{2}{|c|}{$\begin{array}{ll}\text { i. } & \text { using or not using } \\
\text { ii. } & \text { which emotions were } \\
& \text { involved } \\
\text { iii. } & \text { emotional valence }\end{array}$} & $\begin{array}{ll}\text { i. } & \text { using or not using } \\
\text { ii. } & \text { which emotions were } \\
& \text { involved } \\
\text { iii. } & \text { emotional valence }\end{array}$ \\
\hline \multirow[t]{4}{*}{$\begin{array}{l}\text { 3. axial } \\
\text { coding }\end{array}$} & $252^{\mathrm{c}}$ & \multicolumn{3}{|c|}{ 1. The degree of the actual usage of the ERE } \\
\hline & & \multicolumn{2}{|c|}{$\begin{array}{l}0 \text { (didn’t use at all) } \\
1 \\
2 \\
3 \text { (maximal usage) } \\
\end{array}$} & \\
\hline & & \multicolumn{3}{|c|}{ 2. Type of emotional process } \\
\hline & & $\begin{array}{l}\text { a. A learning } \\
\text { process with } \\
\text { unpleasant } \\
\text { academic } \\
\text { emotions }\end{array}$ & $\begin{array}{l}\text { b. A learning } \\
\text { process with } \\
\text { pleasant academic } \\
\text { emotions }\end{array}$ & $\begin{array}{l}\text { c. A learning process with } \\
\text { changes in the emotional } \\
\text { valence }\end{array}$ \\
\hline & & & & $\begin{array}{l}\text { i. from negative to } \\
\text { positive valence } \\
\text { ii. from positive to } \\
\text { negative valence } \\
\text { iii. from positive to } \\
\text { negative and back to } \\
\text { positive valence }\end{array}$ \\
\hline
\end{tabular}




\section{Results}

Sorting the academic emotions that emerged from analyzing the data revealed two main approaches to the use of ERE. In the first approach, the initial preference expressed was not to make use of examples, which we will refer to as the objecting approach. In the second approach, the initial preference expressed was to make use of examples during the learning processes, which we will refer to as the agreeing approach. Each approach is presented as a distinct type of user of the ERE. We named these academic emotional types to differentiate them from personality-based emotional types.

\section{A Mosaic of Academic Emotional Types of Example Users}

During content analysis, we found three objecting types, who expressed unpleasant emotions toward learning in an ERE. The prevalence of each type is presented in Table 2 by percentage: ${ }^{1}$

1. Go alone

2. Threatened

3. Does not want to be influenced

In addition, we found three agreeing types, who found the ERE useful on both cognitive-scholastic and emotional levels. Contrary to the objecting-type students, the agreeing-type students expressed pleasant emotions regarding the learning process and each one used the ERE in her own unique way:

\section{Needs an example \\ 5. Frustrated learner \\ 6. Enthusiastic}

In isolated cases, combination types were found (see Footnote 1), such as between "Does not want to be influenced" and "Needs an example", or between "Needs an example" and "Enthusiastic". Notably, we were unable to determine a definite type for about only $1 \%$ of participants.

In the following section, we will present the types and their characteristics according to their frequency of usage of the ERE (from low to high), beginning with the "objecting" group.

Type 1: Go alone. From the outset, when we began learning in the ERE, the "Go alone" type strongly objected to using the ERE because she felt able to cope with the tasks independently. Students belonging to this type often used expressions such as "by myself", "mine", "independently", and "alone", as illustrated by Emma's words: "When I work alone, I believe that my learning method is the best one for me. To internalize the learning, I prefer to work alone; I don't need examples".

${ }^{1}$ Two students were characterized as belonging to more than one type, which is why the prevalence sum is greater than $100 \%$. 
It can be said that this type of student was "immune" to our explicit instruction to peruse the examples. She wished to perform tasks on her own, and to undergo a personal specialization process. For the "Go alone" type, studying the ERE aroused unpleasant academic emotions, and that negative emotional valence did not change throughout the entire learning process in the ERE.

Type 2: Threatened. This type objected to perusing the examples, felt threatened, anxious, and experienced unpleasant emotions on encountering examples created by others. This type of student was task-focused and expressed a sense of inferiority compared to the creators of the examples in the ERE: "[The examples] really messed me up by their level of precision and design. Challenging examples stress me out". (Jane).

Similarly to the "Go alone" type, students of the "Threatened" type did not use the ERE. Through observing the way in which the students worked in the ERE, we saw that, in the first questionnaire, this type of student agreed to make use of the ERE. However, after glancing at several examples and conducting a stressful and threatening comparison with her own performance, she declared that she would look at no more examples. For the "Threatened" type, studying the ERE changed their emotional valence from positive to negative.

Type 3: Does not want to be influenced. This type of students constituted the largest group among the study participants. Students of this type were afraid that looking at previous students' examples would influence their creative process. They expressed the intense wish to undergo the process independently and to produce a personal, original result, which influenced their use of the ERE. This comes to the fore in statements such as: "I'm the one who has to reinvent the wheel" (Laurie). "I didn't want to damage my ability for creative thinking, but wanted to find the ideas myself. I looked at the examples only because I was asked to" (Lisa).

The words recurring in this type of student's answers expressed the fear that the personal creative process would be damaged and blocked. Some students were even willing to compromise by producing an inferior outcome for the sake of undergoing an individual specialization process, which the outcome would reflect. Some students expressed feelings similar to those of the "Threatened" type. They made very little use of the examples, only when compelled to do so, felt dissatisfied and even sometimes expressed anger. For the "Does not want to be influenced" type, studying the ERE aroused unpleasant academic emotions; they experienced no change and remained as a negative valence throughout the entire learning process.

In conclusion, the objecting group moved between those who felt absolutely no need to look at the examples as they considered themselves able to cope with the task and those who felt that it would threaten their ability to create knowledge, or would threaten their creative process.

In the next section, we will describe the "agreeing" group, who had a pleasant experience of learning in the ERE.

Type 4: Needs an example. Type 4 students were conspicuous during the observations. They were apprehensive about the given task, and immediately 
on receiving the instructions, asked to see examples to perform the task as required. Studying the ERE changed the emotional valence from negative to positive, relaxed these students and increased their sense of performance readiness in two ways: a. the examples clarified the task requirements, $b$. looking at the examples gave them more confidence in their ability to perform the task successfully, as described by the following students:

"I felt relieved because it helped to clear the mist and I understood what I was supposed to do. " (Lizzie)

"I thought that I wouldn't succeed in processing and summarizing the material, but after checking other examples, I saw that it was possible." (Paula)

Students who belonged to the "Needs an example" type made goal-focused use of the ERE to clarify what was expected of them in each individual task. As the process advanced, they even became enthusiastic about example-based learning.

Type 5: Frustrated learner. In the first questionnaire, this type of student responded that she would readily study the ERE because she was focused on accurate task performance. However, after attempting to study the examples, she became frustrated by comparing her own work with that of others. The frustration motivated her to learn, however, as shown in the following quotes:

"I blamed myself for omitting such simple information [. . .] [I felt] challenged; I can do this, too, with a bit of work [. . .] I remembered my strong points, which would be expressed in my final result, and it came out even better than the example that had impressed me so much." (Shirley)

This type of student expressed frustration when viewing knowledge that had been formulated and constructed by others with similar intellectual capabilities because of the quality of the knowledge and its mode of presentation. However, "Frustrated learner" students did not let the frustration prevail but channeled it into study motivation. Studying the ERE changed their emotional valence from positive to negative and then back to positive. The students interacted with many examples and discovered that they were capable of creating results as good as those created by students in previous years.

Type 6: Enthusiastic. This type of student related to the ERE as a gift preceding the learning. The "Enthusiastic" type student did not usually limit herself to specific examples. She saw the perusal of the ERE as an important stage in constructing her own knowledge. This type of student emphasized how much she enjoyed the rich variety of possibilities: "And I very much enjoyed learning about other creative ways and benefiting from the work of my predecessors" (Carol).

The "Enthusiastic" type student was interested to "see a lot". They also described their joy and gratitude in learning from the examples, as reflected in the expressions and metaphors used by Katie: 
"I was very happy to hear and to see other people's outcomes, to expand, to upgrade, to correct, to feel humble, part of something bigger, not only that I am creating outcomes but that there are others[...] I am grateful to them." (Katie)

The "Enthusiastic" type student felt part of the learning community. She had imaginary conversations with others, actually seeing and hearing them in her mind. For the "Enthusiastic" type, studying the ERE aroused pleasant academic emotions; she experienced no change and remained as a positive valence throughout the entire learning process.

Different academic emotions and different emotional processes were found to activate the six user types of ERE presented in their example-based learning process. These emotions were documented in the observations and continued to appear in all of the questionnaires following varied tasks. This finding emphasized the consistency of each user type's approach to the ERE. Table 2 presents the actual degree of usage of the ERE by each type, on a scale from 0 to 3 (where 3 = maximum use of the ERE) and the participants' type of emotional process experienced while learning in an ERE.

Table 2. Characterization of Academic Emotional Types in an ERE

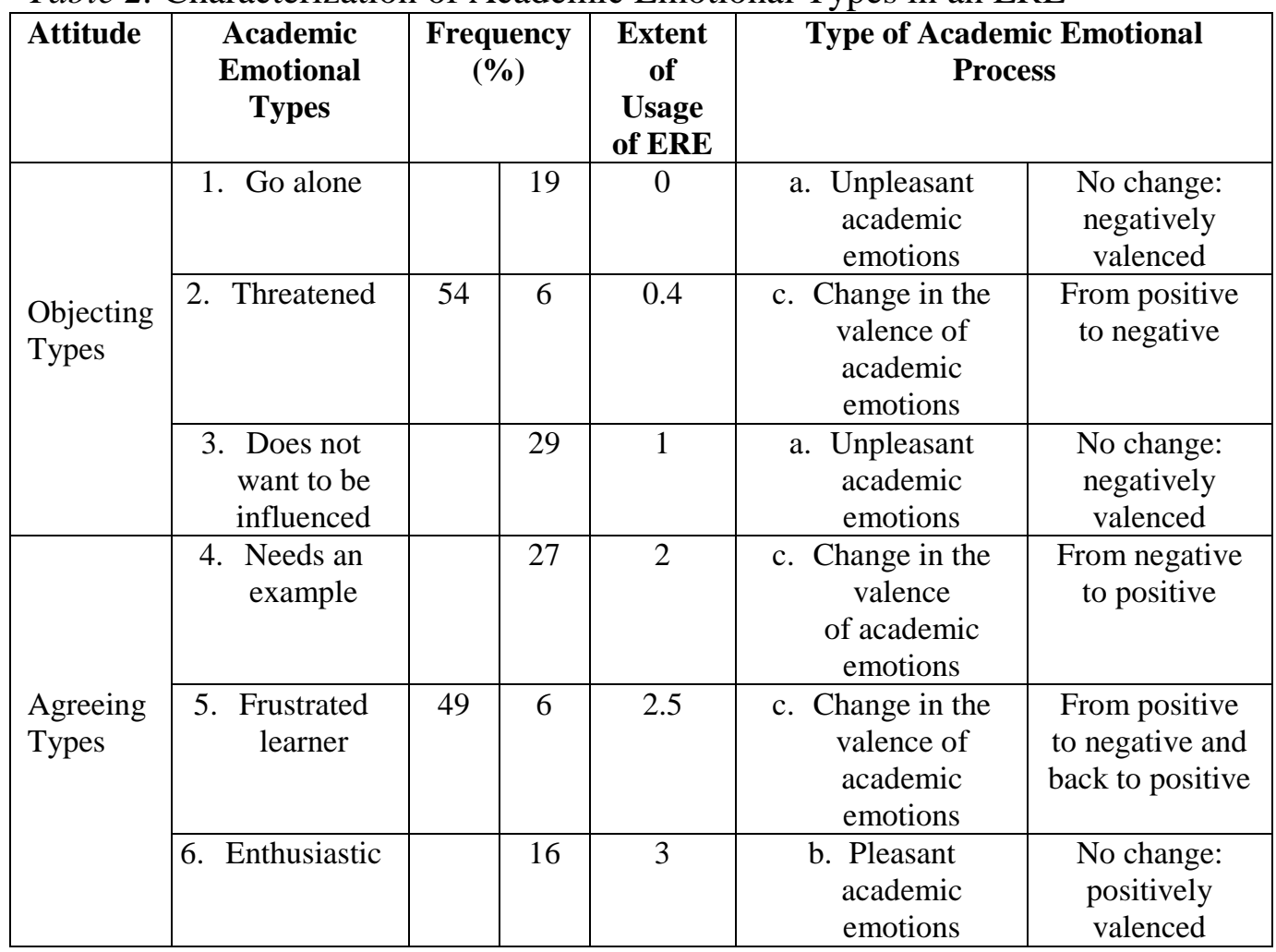

The ERE exposed the differences among the academic emotional types. These differences were expressed in the extent to which each type used the ERE and in the academic emotional process that each type experienced in the ERE. We identified three types of academic emotional processes: a. A learning 
process in which unpleasant academic emotions were aroused in relation to learning in an ERE (experienced by the "Go alone" and "Does not want to be influenced" types); b. A learning process in which pleasant academic emotions were aroused toward learning in an ERE (experienced by "Enthusiastic" type); c. A learning process that was characterized by changes in the emotional valence with which the students entered the ERE: i. From positive to negative; ii. From negative to positive; iii. From positive to negative and back to positive (experienced by the "Threatened", "Needs an example", and "Frustrated learner" types).

The data analysis makes clear that learning through examples created by others is not a trivial process.

\section{Discussion}

Our purpose for the present study was to understand the academic emotions experienced by students during a learning process in an ERE. We expected to advance the theoretical and practical knowledge of the role of emotions in an academic-learning-environment context, which included learning from examples.

The data analysis revealed varied expressions of academic emotions during learning in an ERE. These expressions reflected the multifaceted phenomenon of academic emotions (Pekrun \& Linnenbrink-Garcia, 2012). We found expressions of happiness and fear, interest and understanding; emotions reflecting the degree of enjoyment and emotional arousal during the learning process, and emotions relating to physical sensations while learning. All these were also manifest in the students' gestures and language.

Sorting the academic emotions that were expressed showed that the types of emotions could be characterized according to a bipolar dimension of valence (negative vs. positive). The academic emotions aroused regarding the examplebased environment reflected the valence of emotions, from unpleasantness to a state of pleasantness.

The characterization of the emotions led to a distinction between two approaches toward learning in an ERE (objecting/agreeing). We identified three "objecting" types and three "agreeing" types, each of which demonstrated its own characteristic behavior in the ERE. Tracing the emotions expressed at different points during the learning process led to the characterization of three types of academic emotional processes in the ERE: positive, negative, and changing. This category of emotional processes experienced by learners in an ERE was reflected on final account in their actual usage of the examples (3 degrees). When exposed to the viewpoint of the research dealing with academic emotions, we found an additional, surprising dimension, using the concept of achievement goals. This concept explained the behavior in the ERE. 


\section{Achievement Goals}

Examining the six types via the achievement-goal-focused theory (Dweck, 1999; Meyer \& Turner, 2006; Pekrun, Elliot \& Maier, 2009) added further depth to understanding the academic emotional types. While observing the three academic emotional processes described above by means of the theory dealing with achievement goals, we discovered that change or no change in the emotional process was a crucial factor. Now we could characterize two new groups that we had not distinguished at first glance. One includes the three types who did not experience an emotional change during the learning in the example-based environment $(64 \%)$ and the other includes those who underwent an emotional change as a result of the example-based learning environment (39\%). The "Go alone", "Does not want to be influenced", and the "Enthusiastic" types, who did not undergo an emotional change, were focused on mastery goals. The "Go alone" and "Does not want to be influenced" types, who belonged to the objecting group, felt that the example-based environment might obstruct their individual learning process. The "Enthusiastic" type, however, felt that the example-based environment enhanced the possibility of mastery in the area under study.

In contrast, students belonging to the "Threatened", "Frustrated learner" and "Needs an example" types were focused on performance goals. The encounter with the ERE caused them to compare their performance with that of others presented in the examples. That comparison evoked change in their academic emotions: For the "Threatened" and "Frustrated learner" types, the encounter with the examples shifted the emotional valence from positive to negative. The "Frustrated learners" swayed between positive and negative academic emotions, and succeeded in moving from feelings of frustration to feelings of self-efficacy and pleasant academic emotions. For the "Needs an example" type, the examples provided a response to their academic needs, and caused a change from negative to positive emotional valence.

An observation of the six academic emotional types through the achievement goals dimension explained the academic-emotional changes that occurred during the learning process in the ERE, while emphasizing the complexity of each type. For example, two types were found to focus on the mastery goals, but the extent of usage were opposite: "Go alone" was an objecting type who did not make use of examples, whereas "Enthusiastic" was an agreeing type and made extensive use of examples. These findings emphasized that the achievement goals dimension was not found to have oneto-one congruence with the extent to which examples were used.

Figure 1 presents each type's actual extent of usage of the ERE, by scoring on a scale from 0 to 3, while relating to each type's achievement goals. The hat icon shows the schematic representation of the mastery-focused goals and the $\checkmark$ check shows the schematic representation of the performance-focused goals. 
Figure 1. A Mosaic of Academic Emotional Types: The Extent of Usage of the ERE and the Achievement Goal of Each Type

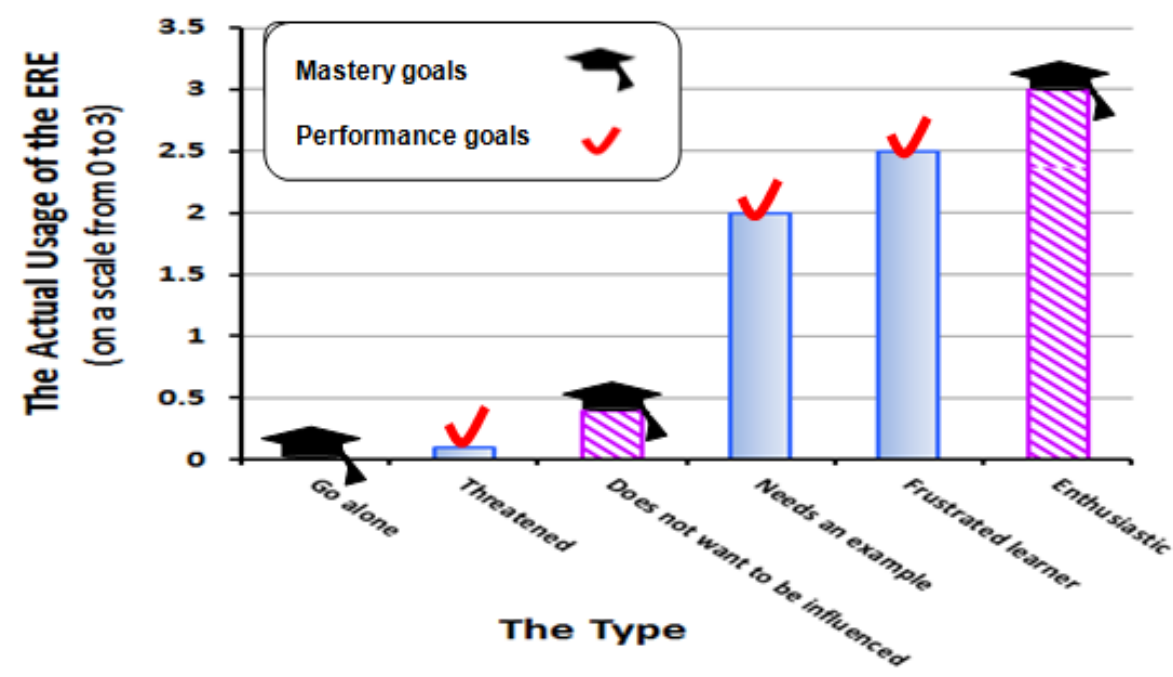

In Figure 1, it is evident that the "Does not want to be influenced" type and the "Go alone" type, who belong to the objecting group, and who scarcely used the ERE, were working toward mastery goals. The other two types, "Needs an example" and "Frustrated learner", who did make use of the examples, were working toward performance goals. Hence, the actual extent of example usage, which was an external criterion for division into two groups-either agreeing or objecting to using examples-does not reflect each type's internal motivation for learning.

\section{Conclusion}

From the above description, it appears that the type of achievement goals focused on by each user type was an important dimension in the academic emotions expressed in the ERE. Moreover, learning in an ERE was found to enable a profound distinction between two groups of types, with masteryfocused students on one pole and performance-focused students on the other. That the dimension relating to mastery-focused goals was found to be an important overarching category, which throws light on the motivation for external behavior.

Thus it was found that the environment revealed a large group of masteryfocused students, only some of whom made extensive use of examples, while the majority made little or no use of examples. In contrast, in the performancefocused group of students, most used the examples and only a few hardly made use of examples. In other words, students' external behavior in an ERE does not reflect their motivations for using or not using examples.

These findings show that academic emotions regarding learning in an ERE 
constitute a multifaceted phenomenon, with external-behavioral expression (actual use of examples) and deeper, internal expression (type of achievement goals).

\section{Implications}

The six academic emotional types identified in our study were each activated by their unique academic emotions. These were related to each one's focused achievement goals aroused in the ERE. Variance in this dimension might characterize a variety of students in example-rich computerized environments and might explain the degree of willingness to use this environment.

In light of this, the complexity of the academic emotional types adds to the discussion of the issue of effective teaching methods in an ERE. Awareness of the mosaic of academic emotional types, especially in the Information Age, suggests the importance of designing differential pedagogy tailored to the needs of a range of academic emotional types.

The present study is a qualitative research conducted in the context of an academic course at a college of education. The participants were characterized by academic and professional maturity and generally highly motivated to learn. It invites researchers of education to attempt to characterize the weight of the motivational dimension as well as the unique weight of each individual dimension in the range of academic emotions in an ERE. Moreover, it will be interesting to track the behavior of students in various EREs, including examination of the disciplinary aspect. This will help enrich our insights concerning the modes of motivational and academic emotional expression that shape the mosaic of types in example-rich environments.

\section{Acknowledgements}

This research was supported by the Michlalah Jerusalem College and the Inter-Collegiate Research Committee in the MOFET institute. We thank all the students who participated in the Learning Processes courses from 2010 to 2013 at the Center for the Development of Thinking and Learning, for their openness to learning a different approach.

\section{References}

Ausubel, D. P. (1968). Educational psychology: A cognitive view. New York: Holt, Rinehart \& Winston.

Atkinson, R. K., \& Renkl, A. (2007). Interactive example-based learning environments: Using interactive elements to encourage effective processing of worked examples. Educational Psychology Review, 19, 375-386. http://dx.doi. org/10.1007/s10648-007-9055-2. 
Bandura, A. (Ed.). (1971). Psychological modeling: Conflicting theories. New York: Aldine-Atherton.

Barrett, L. F., \& Russell, J. A. (1998). Independence and bipolarity in the structure of current affect. Journal of Personality and Social Psychology, 74(4), 967-984. http://dx.doi.org/10.1037/0022-3514.74.4.967.

Charmaz, K. (2006). Constructing grounded theory (2nd ed.). Thousand Oaks, CA: Sage.

Corbin, J., \& Strauss, A. (1998). Basics of qualitative research: Techniques and procedures for developing grounded theory (4th ed.). Thousand Oaks, CA: Sage.

Dweck, C. S. (1999). Self-theories: Their role in motivation, personality, and development. Philadelphia, PA: Psychology Press/Taylor and Francis.

Hargreaves, A. (2000). Mixed emotions: Teachers' perceptions of their interactions with students. Teaching and Teacher Education, 16, 811-826. http://dx.doi.org/10. 1016/s0742-051x(00)00028-7.

Kalyuga, S., \& Sweller, J. (2004). Measuring knowledge to optimize cognitive load factors during instruction. Journal of Educational Psychology, 96, 558-568. http://dx.doi.org/10.1037/0022-0663.96.3.558.

Linnenbrink, E. A. (2006). Emotion research in education: Theoretical and methodological perspectives on the integration of affect, motivation, and cognition. Educational Psychology Review, 18(4), 307-314 http://dx.doi.org/ 10.1007/s10648-006-9028-x.

Linnenbrink, E. A., \& Pintrich, P. (2003). The role of self-efficacy beliefs in student engagement and learning in the classroom. Reading and Writing Quarterly, 19, 119-137. http://dx.doi.org/10.1080/10573560308223.

McGregor, H. A., \& Elliot, A. J. (2002). Achievement goals as predictors of achievement-relevant processes prior to task engagement. Journal of Educational Psychology, 94, 381-395. http://dx.doi.org/10.1037/0022-0663.94.2.381.

Meyer, D. K., \& Turner, J. C. (2006). Re-conceptualizing emotion and motivation to learn in classroom contexts. Educational Psychology Review, 18, 377-390. http://dx.doi.org/10.1007/s10648-006-9032-1

Patton, M. Q. (2002). Qualitative research \& evaluation methods (3rd ed.). Thousand Oaks, CA: Sage.

Pekrun, R., Elliot, A. J., \& Maier, M. A. (2009). Achievement goals and achievement emotions: Testing a model of their joint relations with academic performance. Journal of Educational Psychology, 101(1), 115-135. http://dx.doi.org/10.1037/ a0013383.

Pekrun, R., \& Frese, M. (1992). Emotions in work and achievement. In C. L. Cooper \& I. T. Robertson (Eds.), International review of industrial and organizational psychology, Vol. 7, (pp. 153-200). Chichester, UK: Wiley. http://dx.doi.org/10. 1177/017084069401500213.

Pekrun, R., Goetz, T., Titz, W., \& Perry, R. (2002). Academic emotions in students' self-regulated learning and achievement: A program of qualitative and quantitative research. Educational Psychologist, 37(2), 91-105. http://dx.doi.org/ 10.1207/s15326985ep3702_4.

Pekrun, R., \& Linnenbrink-Garcia, L. (2012). Academic emotions and students' engagement. In S. L. Christenson, A. L. Reschly, \& C. Wylie (Eds.), The Handbook of research on student engagement (pp. 259-282). New York: Springer. http://dx.doi.org/10.1007/978-1-4614-2018-7_12.

Pekrun, R., \& Perry, R. P. (2014). Control-value theory of achievement emotions. In R. Pekrun \& L. LinnenbrinkGarcia (Eds.), International handbook of emotions in education (pp. 120-141). New York, NY: Taylor \& Francis. 
Pugh, K. J., \& Bergin, D. A. (2006). Motivational influences on transfer. Educational Psychologist, 41(3), 147-160. http://dx.doi.org/10.1207/s15326985ep4103_2.

Senko, C., Hulleman, C. S., \& Harackiewicz, J. M. (2011). Achievement goal theory at the crossroads: Old controversies, current challenges, and new directions. Educational Psychologist, 46(1), 26-47. http://dx.doi.org/10.1080/00461520.20 11.538646.

Sung, K., \& Poggio, T. (1998). Example-based learning for view based human face detection. IEEE Transaction on Pattern Analysis and Machine Intelligence, 20(1), 39-51. http://dx.doi.org/10.1109/34.655648.

van Gog, T. \& Rummel, N. (2010). Example-based learning: Integrating cognitive and social-cognitive research perspectives. Educational Psychology Review, 22(2), 155-174. http://dx.doi.org/10.1007/s10648-010-9134-7.

Vinner, S. (1983). Concept definition, concept image and the notion of function. International Journal of Mathematics Education, Science and Technology, 14(3), 293-305. http://dx.doi.org/10.1080/0020739830140305.

Vinner, S. (2011). The role of examples in the learning of mathematics and in everyday thought processes. ZDM Mathematics Education, 43(2), 247-256. http://dx.doi.org/10.1007/s11858-010-0304-3.

Zeidner, M. (2007). Test anxiety in educational contexts: Concepts, findings, and future directions. In P. A. Schutz \& R. Pekrun (Eds.), Emotion in education (pp. 165-184). San Diego, CA: Academic Press. http://dx.doi.org/10.1016/B978012372545-5/50011-3.

Zocco, D. (2009). Risk theory and student course selection. Research in Higher Education Journal, 3, 1-29. 